\title{
Influence of Barley Sourdough and Vacuum Cooling on Shelf Life Quality of Partially Baked Bread
}

\author{
Dubravka Novotni ${ }^{1}$ Ivna Vrana Špoljarić ${ }^{2}$ Saša Drakula ${ }^{1}$, Nikolina Čukelj ${ }^{1 *}$, Bojana \\ Voučko ${ }^{1}$, Mario Ščetar ${ }^{1}$, Kata Galić ${ }^{1}$ and Duška Curić ${ }^{1}$ \\ ${ }^{1}$ University of Zagreb, Faculty of Food Technology and Biotechnology, \\ Pierottijeva 6, HR-10000, Zagreb, Croatia \\ ${ }^{2}$ University of Zagreb, Faculty of Food Technology and Biotechnology, Food Control Centre, \\ Jagićeva 31, HR-10000 Zagreb, Croatia
}

Received: May 12, 2017

Accepted: July 21, 2017

\begin{abstract}
Summary
Driven by the bakery industry urge to satisfy consumer demand for fresh, diverse and high quality bakery products, we investigated the influence of barley sourdough and vacuum cooling on shelf life quality of partially baked bread stored in modified atmosphere packaging at ambient conditions. Barley sourdough was fermented with Lactobacillus reuteri (DSM 20016, F275). Partially baked bread with sourdough was microbiologically acceptable during 30 days of storage, while bread without sourdough had detectable mould on the 30th day. Stored bread samples were rebaked after 1, 8, 15, 22 and 30 days to determine moisture content, physical and sensorial properties. Moisture loss (5\%) was detected on the 15 th day, after which it remained stable until the end of investigated storage period. Nevertheless, textural quality of stored bread continuously declined due to crumb firming. Bread flavour did not change during mould-free storage time. The principal component analysis identified major differences in the flavour of sour and control bread, also in crumb firmness and moisture content of samples. This study indicates the positive role of barley sourdough fermented with L. reuteri in improving crumb texture for at least 15 days, and ensuring mould- and bacteria-free partially baked bread for 30 days. Vacuum cooling combined with sourdough improved bread shape, porosity, and reduced sour taste, crust colouring and crumbliness. Hence, it can successfully extend shelf life quality of partially baked bread in modified atmosphere packaging.
\end{abstract}

Key words: barley sourdough bread, crumb firmness, Lactobacillus reuteri, modified atmosphere packaging, principal component analysis, vacuum cooling

\section{Introduction}

The short shelf life of bread is mainly caused by its staling and microbial spoilage (1). As bread stales during storage, its aroma vanishes, crust softens, crumb hardens and becomes crumbly, and consumer acceptance diminishes. Besides, if bread is stored for several days, mould growth and ropiness caused by Bacillus subtilis occur. In order to lessen bread waste, different improvers and methods, in- cluding low temperatures and packaging, have been applied. Cereal materials such as barley flour or isolated $\beta$-glucans might retard bread staling as well $(2,3)$. In spite of that, barley flour has limited application in bread-making because it lessens the volume and diminishes crumb structure (4). Most researchers recommend the addition of 15-20\% barley flour into wheat bread (5), although trials with $100 \%$ barley bread have also been conducted (6). 
Another traditional method which extends bread shelf life is sourdough application $(7,8)$. In addition to extending shelf life, sourdough, e.g. from whole grain barley flour, might be used as an improving agent in composite wheat bread (9). Application of barley sourdough (approx. 24\%) enhances unique nutritional value of barley flour and improves technological and sensory quality of bread (6), but to our knowledge, its application for extension of bread shelf life has not been explored yet.

During the last decade the functional starter cultures producing different bioactives have become interesting as natural controllers of bakery product shelf life and safety (10). For example, Lactobacillus reuteri is one of the functional starters that produce reuterin, an inhibitor of Aspergillus and Fusarium mould growth $(7,11)$, and exopolysaccharides (EPS), which are prebiotics and staling retarders $(12,13)$. In our previous work $(14)$, we found L. reuteri suitable for barley sourdough fermentation. Nevertheless, the synergistic effect of L. reuteri and barley flour on bread quality during prolonged storage is still uncertain.

For considerable extension of bread shelf life, par-baked technology or interrupted baking process has been developed. Whether partially baked bread is stored at freezing, cold or ambient temperatures, it has a direct impact on its shelf life and quality. Lower temperatures above freezing point prolong shelf life but increase staling, while higher temperatures slow down staling but favour microbial spoilage (15). Subzero storage temperatures substantially prolong microbial shelf life and retard staling (16); however, this method demands high production, storage and distribution energy (17), as well as specific bread improvers. Compared to freezing, modified atmosphere packaging (MAP) of bakery products can reduce energy consumption by $18-20 \%$ (1). The addition of natural preservatives originating from sourdough might further increase MAP efficiency.

Before packing, partially baked bread is cooled down to storage temperature to avoid moisture condensation. The cooling process itself presents a spoilage risk. Therefore, a rapid technique, vacuum cooling has been introduced to bakery industry. Its major advantages are increased productivity, reduced energy consumption and possible contribution to longer shelf life $(18,19)$. Up to date, there has been little agreement whether vacuum cooling positively or negatively affects shelf life quality of conventionally baked bakery products. Wang and Sun (18) reported that vacuum-cooled baked products are less susceptible to contraction and collapse during storage, Primo-Martín et al. (20) described positive effect of vacuum cooling on crust crispness but negative effect on crumb hardness, and Le-Bail et al. (21) showed that vacuum-cooled whole wheat bread with sourdough stales faster than conventionally cooled bread.

The aim of this study is to assess separate and combined impact of barley sourdough addition (20\%) and vacuum cooling on the quality of partially baked bread stored in MAP for 30 days at ambient conditions. Moreover, the effect of synergy of barley flour and L. reuteri on sourdough fermentation was investigated for the possibility of delaying firming and microbial spoilage of composite wheat bread. Characteristics of fresh bread (volume, shape, crumb structure, crust colour) and stored bread (microbial count, moisture content, crumb firmness, sensory attributes) were analysed.

\section{Materials and Methods}

\section{Flour types}

We used commercial wheat flour (Žitoproizvod, Karlovac, Croatia) and whole grain barley flour (Advent, Pula, Croatia) with 0.7 and $1.15 \%$ ash, and 12.4 and $10.0 \%$ proteins, respectively. Amylograph maximum viscosities were 1200 Brabender Units (BU) for wheat and 1730 BU for barley flour (22). Farinograph characteristics of wheat flour (23) were: water absorption $61 \%$, stability $1 \mathrm{~min}$, and degree of softening 70 BU. Extensograph characteristics (24) of this flour after 45 and 90 min of resting were respectively as follows: maximum resistance 315 and $360 \mathrm{BU}$, extensibility 163 and $152 \mathrm{~mm}$, energy 65.5 and $69.3 \mathrm{~cm}^{2}$, and resistance to extensibility ratio 1.3 and 1.7 .

\section{Sourdough preparation, cell count and acidity determination}

MRS broth (de Man, Rogosa and Sharpe; Biolife, Bolzano, Italy) was inoculated with the overnight culture of Lactobacillus reuteri DSM 20016 and incubated for $48 \mathrm{~h}$ at $37^{\circ} \mathrm{C}$. After centrifugation at $2000 \times g$ for $10 \mathrm{~min}$ (Rotina 35; Hettich, Tuttlingen, Germany), lactic acid bacteria (LAB) cells were used to inoculate the sourdough.

Barley flour (600 g) was mixed with water (total $900 \mathrm{~g}$, taking into account the amount of water in the inoculum) and the inoculum of L. reuteri (approx. 6 log colony forming units (CFU) per gram). Sourdough was fermented for 15 $h$ at $37^{\circ} \mathrm{C}$ when $\mathrm{pH}=4.0 \pm 0.1$ was reached. Sourdough was stored at $4{ }^{\circ} \mathrm{C}$ and used in baking within $2 \mathrm{~h}$.

Viable Lactobacillus cells in inoculum and sourdough were enumerated under anaerobic conditions at $37^{\circ} \mathrm{C}(25)$.

Total titratable acidity (TTA) of sourdough was determined as the volume of $0.1 \mathrm{M}$ sodium hydroxide solution necessary to adjust the $\mathrm{pH}$ of $10 \mathrm{~g}$ of sample in $90 \mathrm{~mL}$ of distilled water to $8.5(8)$.

\section{Bread making and samples}

Following full factorial experimental plan, four types of bread differing in formulation (with or without sourdough) and cooling process (vacuum or air) were made and stored for $1,8,15,22$ or 30 days. The recipe for the control bread consisted of wheat flour $(520 \mathrm{~g})$, barley flour $(80 \mathrm{~g})$, water (372 g), compressed yeast (12 g), salt (11 g), and bread improver Extrapan special (Kvasac Ltd., Lesaffre Group, Prigorje Brdovečko, Croatia) (2.4 g). Formulation of sourbread was similar to control, but contained $20 \mathrm{~g}$ of barley sourdough per $100 \mathrm{~g}$ of bread dough instead of barley flour and the water was corrected for the amount already contained in the sourdough. All ingredients were mixed for $2 \mathrm{~min}$ slowly and 5 min fast in a spiral mixer SP12 (Diosna Dierks \& Söhne GmbH, Osnabrück, Germany). After resting for 10 min, the dough was divided to 70-gram pieces and proofed in a fermentation chamber (Wiesheu $\mathrm{GmbH}$, Affalterbach, Germany) at $35{ }^{\circ} \mathrm{C}$ and $75 \%$ relative humidity (RH) for 55 
min. Bread was prebaked in deck oven first at $210{ }^{\circ} \mathrm{C}$ for 4 min, at $200{ }^{\circ} \mathrm{C}$ for another $3 \mathrm{~min}$ and at $190{ }^{\circ} \mathrm{C}$ for the last $7 \mathrm{~min}$, with initial steaming $\left(1.9 \mathrm{dm}^{3} / \mathrm{m}^{3}\right)$. Each formulation was baked in five batches.

Bread samples were cooled at ambient conditions or in a laboratory vacuum chamber, until bread core reached $20{ }^{\circ} \mathrm{C}$ (Fig. 1a). Vacuum chamber was made of stainless steel, double-walled (Fig. 1b), thermostated externally to $-10{ }^{\circ} \mathrm{C}$ by refrigeration bath circulator Huber CC-515 (Huber Kältemaschinenbau $\mathrm{GmbH}$, Offenburg, Germany), and connected to the vacuum pump (LVS 105 T - 10 ef; Ilmvac, Ilmenau, Germany). Bread core temperature was monitored continuously and recorded with data logger (OM-CP-QUADTEMP-A; Omega Engineering, Norwalk, CT, USA). Each partially baked bread, previously surface sprayed with ethanol (approx. $0.1 \mathrm{~g}$ of $96 \%$ ethanol, by volume) was placed in polyamide/polyethylene (PA/PE) pouch. All samples were stored in MAP at ambient temperature of $(21 \pm 2)^{\circ} \mathrm{C}$. After $1,8,15,22$ and 30 days of storage, microbial quality of two randomly chosen partially baked bread samples was examined, while five samples were rebaked to measure baking loss, moisture content and physical properties. Vacuum-cooled samples were rebaked for $10 \mathrm{~min}$, whereas air-cooled samples were rebaked for $11 \mathrm{~min}$ at $230{ }^{\circ} \mathrm{C}$ with $30 \mathrm{~mL}$ of steam.

a)

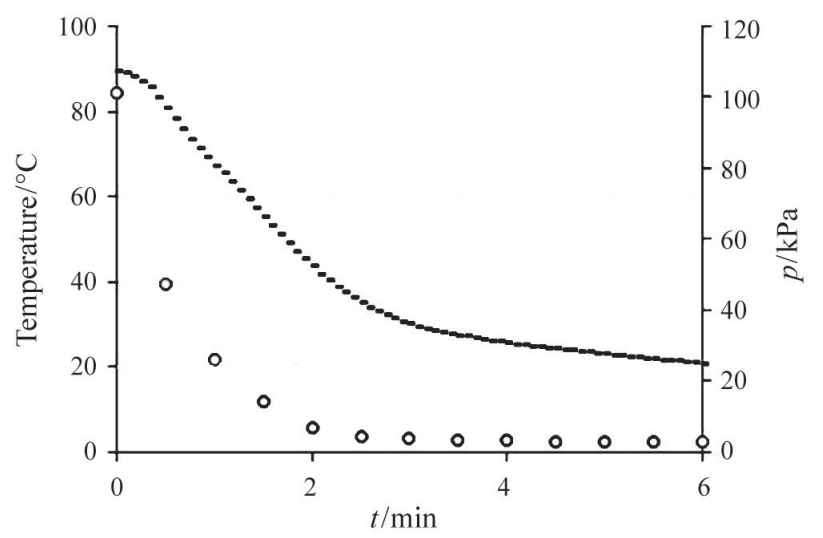

b)

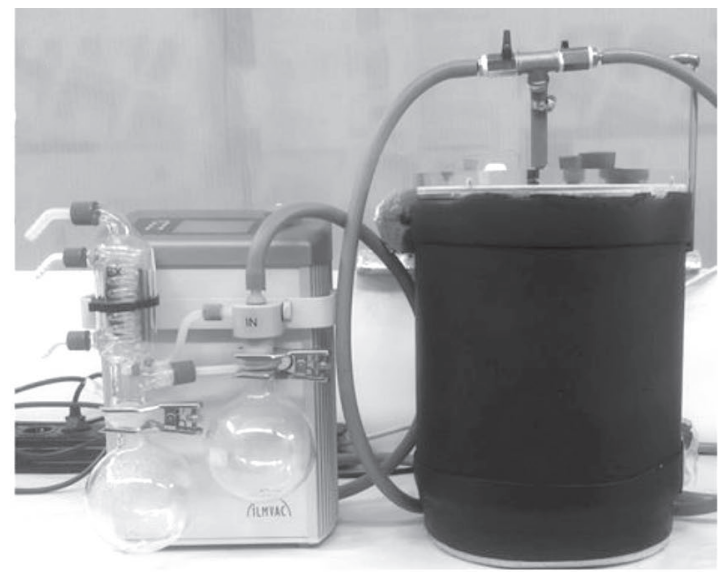

Fig. 1. a) Graph showing pressure (circles) and temperature (dashes) time curves during vacuum cooling of partially baked bread (average value of two measurements) in: b) laboratory vacuum chamber connected to a vacuum pump

\section{Modified atmosphere packaging}

For packaging, $90 \mu \mathrm{m}$ thick, $0.225 \mathrm{~m} \times 0.250 \mathrm{~m} \mathrm{PA} / \mathrm{PE}$ pouches (Dora-Pak, Zagreb, Croatia) with gas permeabilities of $P\left(\mathrm{O}_{2}\right)=2.2 \cdot 10^{-4} \mathrm{~cm}^{3} /\left(\mathrm{mm} \cdot \mathrm{m}^{2} \cdot\right.$ day $\left.\cdot \mathrm{Pa}\right), P\left(\mathrm{CO}_{2}\right)=1.6 \cdot 10^{-4} \mathrm{~cm}^{3} /$ $\left(\mathrm{mm} \cdot \mathrm{m}^{2} \cdot\right.$ day $\left.\cdot \mathrm{Pa}\right)$ and $P\left(\mathrm{~N}_{2}\right)=1.2 \cdot 10^{-4} \mathrm{~cm}^{3} /\left(\mathrm{mm} \cdot \mathrm{m}^{2} \cdot\right.$ day $\left.\cdot \mathrm{Pa}\right)$ at $(23 \pm 1){ }^{\circ} \mathrm{C}$, were used. Gas permeability was determined with a manometric method (26), on gas permeability testing appliance model GDP-C (Brugger Feinmechanik GmbH, München, Germany).

Modified atmosphere consisting of $70 \% \mathrm{CO}_{2}$ and $30 \%$ $\mathrm{N}_{2}$ (by volume, analytical tolerance $\pm 2 \%$ ) was supplied by Messer Croatia Plin Ltd. (Zaprešić, Croatia). The packages were vacuumed to $200 \mathrm{~Pa}$, filled under pressure of $250 \mathrm{kPa}$ with a gas premix and heat sealed for $3.5 \mathrm{~s}$ using a MAP packaging chamber (model Junior digit; Besser Vacuum srl., Dignano, UD, Italy) with a gas mixer (KM20-3; WITT-Gasetechnik GmbH \& Co KG, Witten, Germany). The volume of gas inside the package was about twice the volume of the sample. The concentrations of $\mathrm{CO}_{2}$ and $\mathrm{O}_{2}$ in MAP were checked directly by inserting the needle of a handheld digital gas analyser (Oxybaby; WITT-Gasetechnik) in five packages.

\section{Microbiological tests}

For microbiological analyses, packaging was opened aseptically and $10 \mathrm{~g}$ of sample (obtained from different parts of partially baked bread) were homogenized with $90 \mathrm{~mL}$ of sterile physiological saline solution. A 1-mL aliquot from serial dilutions was plated in duplicate on plate count agar supplemented with a drop of cycloheximide solution (Fluka, St. Gallen, Switzerland) for the total aerobic bacterial count and spores of mesophilic bacteria $(27,28)$, while yeast mold agar (Difco, Milano, Italy) was used for mould count (29). Inoculated Petri plates were incubated at $30{ }^{\circ} \mathrm{C}$ for $72 \mathrm{~h}$ in order to determine the total aerobic plate and spore count, or at $25^{\circ} \mathrm{C}$ for 5 days for mould count.

\section{Mass loss}

The total mass loss indicates the loss of mass during bread prebaking, rebaking and cooling steps. It was calculated as the difference between the mass of rebaked and cooled bread and the mass of dough and was divided by the mass of dough. The cooling loss was calculated as the difference in the mass of cooled and hot partially baked bread, and expressed in percentage.

\section{Physicochemical characterisation of bread}

Bread moisture content was determined by two-step drying (30), in duplicate. For determination of physical properties, at least five replicates of each instrumental measurement were carried out on rebaked samples from different batches. Rebaked bread samples were cooled for $1 \mathrm{~h}$ at ambient temperature before analyses. Volume of weighed sample was measured using the rapeseed displacement method (31). Bread specific volume was calculated as volume to mass ratio. Bread shape was determined by measuring its height and diameter with a calliper in five replicates.

Crumb cell characteristics were determined by image analysis using Image software (32) and SilkyPix (33). Two 
central slices $12.5 \mathrm{~cm}$ thick were scanned using a CanoScan 4400F scanner (Canon CEE GmbH, Vienna, Austria) with a resolution of $300 \mathrm{dpi}$. The central field of view $(5 \mathrm{~cm} \times 3.5$ $\mathrm{cm}$, approx. $40 \%$ of slice area) was selected. For each image, the contrast between two phases (pores and solid part) was adjusted. Images were converted to 8-bit grayscale and thresholded using the Otsu's algorithm (34). Pore area fraction, pore density (number of pores $/ \mathrm{cm}^{2}$ ), mean pore area in $\mathrm{mm}^{2}$ and pore size distribution were calculated (35).

Crumb firmness was measured with a Texture Analyser TA.HD (Stable Micro Systems, Surrey, UK) using a 25-mm aluminium probe (36).

Crust colour was evaluated by a colorimeter (Spectrophotometer CH-3500 D; Konica Minolta, Milton Keynes, UK) in the CIELab system (37). The lightness, $L^{*}$, redness, $a^{*}$, and yellowness, $b^{*}$, were the determined colour parameters.

\section{Sensory evaluation}

Sixteen experienced panellists ( 11 females and 5 males, aged 28-52, on average $37 \pm 7$ ) recruited from the Faculty of Food Technology and Biotechnology staff performed quantitative descriptive analysis in a sensory laboratory which fulfils requirements of ISO 8589:2007 standard (38). The sensory attributes selected during preliminary investigations were mostly associated with bread freshness: oral perception of sour, bitter and yeasty taste, unpleasant aftertaste, nasal perception of dusty, mouldy, acid, yeasty, dairy, overall odour intensity, and manual perception of crumbliness. Samples of bread rebaked $1 \mathrm{~h}$ before the evaluation were presented on two separate days, in two sets of five. A quarter of each sample, including the crust and crumb, was presented to panellists with 3-digit random numbers. Intensity of attribute had to be scored in range from 0 (lack of attribute) to 10 (extremely strong intensity of attribute).

\section{Data analysis}

Experimental results were submitted to factorial analysis of variance (ANOVA) to determine statistically significant differences $(\mathrm{p} \leq 0.05)$ between fresh bread samples regarding sourdough addition and cooling procedure, as well as the effect of time on bread quality indices of stored samples. Sensory data were subjected to one-way ANOVA to test statistically significant differences $(\mathrm{p} \leq 0.05)$ among panellists' responses. Tukey's honestly significant difference test indicated significant differences $(\mathrm{p} \leq 0.05)$ between mean values. Principal component analysis (PCA) was performed to describe the variance between the moisture content, shape, crumb firmness and sensory data of stored bread samples. Data analyses were performed with the computer package STATISTICA, v. 12 (39).

\section{Results and Discussion}

\section{Sourdough characteristics}

At the end of sourdough fermentation, LAB viable count was $9.3 \log \mathrm{CFU} / \mathrm{g}$, while TTA was $(12.3 \pm 0.3) \mathrm{mL}$ of $0.1 \mathrm{M} \mathrm{NaOH}$ (data not shown). Cell count is comparable to previous findings on LAB in barley sourdough $(4,6,40)$ while higher than reported for whole wheat sourdough fermented by L. reuteri (41). TTA value of our sourdough was slightly lower than previously reported for barley sourdough $(4,6,40)$. This could be attributed to the applied fermentation conditions, no added yeast and shorter time than in the mentioned studies.

\section{Mass loss during cooling and baking}

Vacuum cooling of bakery products is rapid, and the distribution of the moisture through the loaf is more even (19). After baking, hot bread samples were cooled down to $20^{\circ} \mathrm{C}$ in vacuum chamber for only $6 \mathrm{~min}$ (Fig. 1a), while air cooling lasted $1 \mathrm{~h}$. Nonetheless, cooling mass loss of partially baked bread (Table 1) was significantly higher under vacuum than ambient conditions $(\mathrm{p}<0.001)$. Vacuum cooling of bakery products results in approx. $7 \%$ of mass loss (19) whereas in conventional cooling mass loss is 3 to $5 \%$, which is in agreement with our results. This is due to the fact that vacuum cooling is based on evaporation, whereas conventional cooling is a combination of convective heat transfer and evaporative cooling (21).

Table 1. Mass loss during processing and physical properties of fresh bread samples depending on the sourdough addition and the cooling method

\begin{tabular}{|c|c|c|c|c|}
\hline \multirow{2}{*}{ Parameter } & \multicolumn{2}{|c|}{ Air } & \multicolumn{2}{|c|}{ Vacuum } \\
\hline & Control & Sourdough & Control & Sourdough \\
\hline Cooling mass loss/\% & $(4.1 \pm 0.1)^{\mathrm{b}}$ & $(4.1 \pm 0.2)^{\mathrm{b}}$ & $(5.8 \pm 0.2)^{\mathrm{a}}$ & $(5.8 \pm 0.6)^{\mathrm{a}}$ \\
\hline Total mass loss/\% & $(15.3 \pm 0.7)^{\mathrm{a}}$ & $(15.4 \pm 0.3)^{\mathrm{a}}$ & $(15.7 \pm 0.5)^{\mathrm{a}}$ & $(15.4 \pm 0.2)^{\mathrm{a}}$ \\
\hline Specific volume $/\left(\mathrm{cm}^{3} \cdot \mathrm{g}\right)$ & $(3.24 \pm 0.23)^{\mathrm{a}}$ & $(3.35 \pm 0.24)^{\mathrm{a}}$ & $(3.39 \pm 0.24)^{\mathrm{a}}$ & $(3.41 \pm 0.24)^{\mathrm{a}}$ \\
\hline Shape (height/width) & $(0.57 \pm 0.01)^{\mathrm{a}}$ & $(0.59 \pm 0.01)^{\mathrm{ab}}$ & $(0.58 \pm 0.01)^{\mathrm{ab}}$ & $(0.60 \pm 0.03)^{b}$ \\
\hline Pores area fraction/\% & $(25.9 \pm 2.0)^{\mathrm{ab}}$ & $(25.6 \pm 1.5)^{\mathrm{a}}$ & $(25.7 \pm 1.7)^{\mathrm{a}}$ & $(26.8 \pm 3.0)^{\mathrm{b}}$ \\
\hline Mean cell area $/ \mathrm{mm}^{2}$ & $(0.28 \pm 0.03)^{\mathrm{a}}$ & $(0.28 \pm 0.02)^{\mathrm{a}}$ & $(0.29 \pm 0.02)^{\mathrm{a}}$ & $(0.29 \pm 0.05)^{\mathrm{a}}$ \\
\hline Cell density/(N/mm²) & $(92.1 \pm 4.9)^{\mathrm{a}}$ & $(92.4 \pm 3.0)^{\mathrm{a}}$ & $(88.6 \pm 2.9)^{\mathrm{a}}$ & $(91.9 \pm 4.4)^{\mathrm{a}}$ \\
\hline Crust $L^{*}$ & $(71.4 \pm 2.5)^{\mathrm{ab}}$ & $(69.9 \pm 3.4)^{\mathrm{b}}$ & $(71.2 \pm 2.2)^{\mathrm{ab}}$ & $(71.9 \pm 2.0)^{\mathrm{a}}$ \\
\hline Crust $a^{*}$ & $(10.6 \pm 2.0)^{\mathrm{a}}$ & $(11.5 \pm 2.9)^{\mathrm{a}}$ & $(10.7 \pm 1.8)^{\mathrm{a}}$ & $(10.0 \pm 2.0)^{\mathrm{a}}$ \\
\hline Crust $b^{*}$ & $(36.5 \pm 2.9)^{\mathrm{a}}$ & $(37.1 \pm 2.1)^{\mathrm{a}}$ & $(36.1 \pm 1.4)^{\mathrm{a}}$ & $(36.1 \pm 2.1)^{\mathrm{a}}$ \\
\hline
\end{tabular}

The results are expressed as mean value \pm standard deviation. Different letters within the same row indicate significant differences between mean values as evaluated by Tukey's HSD test $(\mathrm{p}<0.05)$. $N=$ number of cells 
In this study, to compensate for higher mass loss during vacuum cooling, the rebaking time of vacuum-cooled partially baked bread was shortened from 11 to $10 \mathrm{~min}$, resulting in similar total mass loss for all samples (Table 1). Our result confirms the effectiveness of this practice (42) to minimize mass loss due to vacuum cooling.

\section{Physical properties of fresh bread}

Bread volume, shape, crumb structure and crust colour, together with texture and flavour, significantly contribute to consumer acceptability. Bread samples that were stored partially baked in MAP and rebaked the next day were considered 'fresh'. Generally, fresh bread samples did not differ much in physical properties (Table 1). Vacuum-cooled sourbread had the biggest specific volume, but the difference between samples was insignificant $(p>0.05)$. Previously, different effects of sourdough as well as vacuum cooling on bread volume were reported. In agreement with our results, Marklinder et al. (4) reported that the barley bread volume did not improve with sourdough addition, and Zhao et al. (41) stated that the volume of wholemeal wheat bread was not affected with $6 \%$ inclusion of $L$. reuteri-fermented sourdough. Rieder et al. (9) indicated that the use of barley sourdough fermented by L. plantarum (20\% of total flour) can affect bread volume, depending on the barley variety and flour characteristics. Further, Le-Bail et al. (21) found some differences $(<10 \%)$ in the specific volume of crumb between vacuum- and conventionally cooled whole wheat sourdough bread samples, but considered them insignificant.

Bread shape (height/width) was positively affected by sourdough addition $(\mathrm{p}=0.006)$. This could be attributed to exopolysaccharides (EPS) formed in sourdough, since they are known improvers of dough viscoelastic properties (13). The shape was even higher when sourdough bread was vacuum cooled. Still, shape differences among samples were within $3 \%$.

Bread structure is determined by raw materials and processing conditions. Scans of selected slices of each bread and their thresholded images are shown in Fig. 2. The interaction of sourdough addition and vacuum cooling significantly increased pore area fraction $(\mathrm{p}=0.04)(\mathrm{Ta}-$ ble 1), and positively correlated with the mean pore area $(\mathrm{R}=0.93 ; \mathrm{p}=0.001)$. Still, the differences in the pore area fraction were $<4 \%$, whereas the pore density did not significantly differ between samples. Our results agree with those of Crowley et al. (35), who claimed that crumb structure of bread containing $20 \%$ sourdough is comparable to standard bread. We found that fresh vacuum-cooled bread had fewer of the smallest pores $\left(0.01-0.09 \mathrm{~mm}^{2}, \mathrm{p}=0.04\right)$, but more of the medium-sized pores $\left(0.1-1.0 \mathrm{~mm}^{2}, \mathrm{p}=0.01\right)$ than air-cooled samples (Fig. 3). Vacuum-cooled control bread and air-cooled sourbread differed the most in the percentage of small pore fractions $(\mathrm{p}<0.05)$, while air-cooled sourbread had more of the smallest pores $\left(0.01-0.09 \mathrm{~mm}^{2}\right)$, vacuum-cooled control bread contained higher percentage of 0.1-1.0 $\mathrm{mm}^{2}$ pores. During cooling, bread volume contracts, as evidenced by Ben Aissa et al. (43). The extent of contraction depends on baking time: the shorter the baking time, the larger the crumb contraction. In the case of

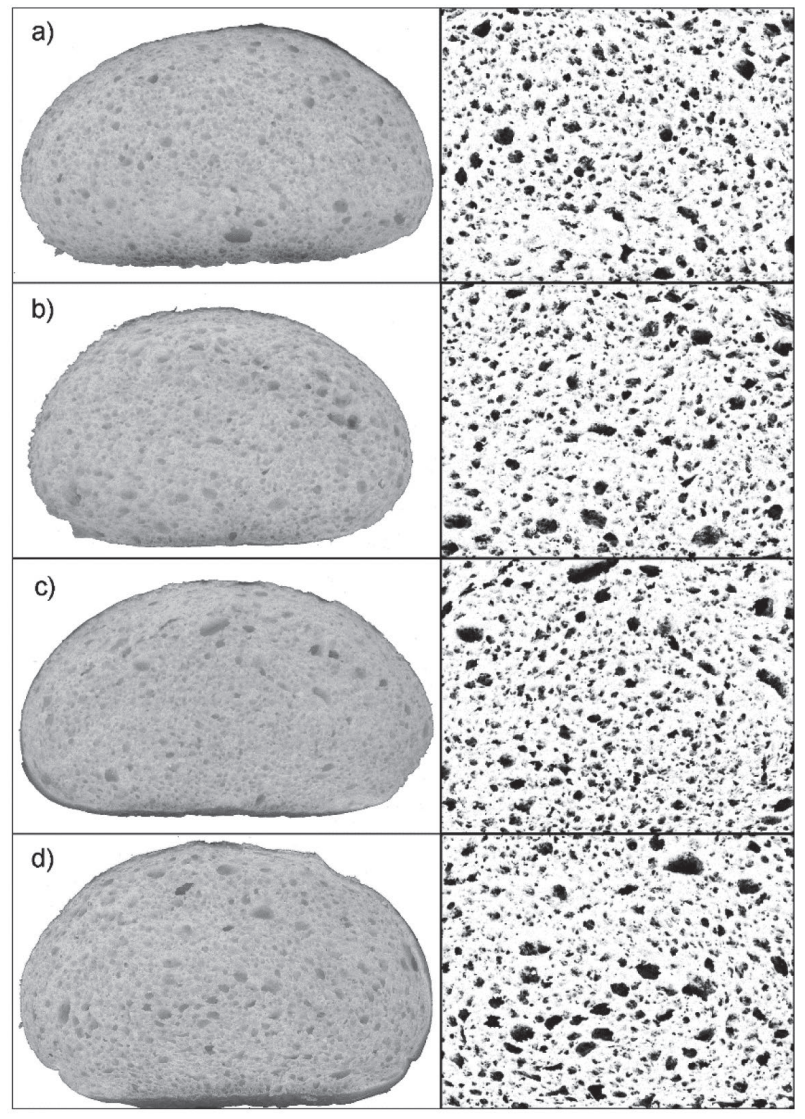

Fig. 2. Scanned images of bread slices (left) and threshold crop images (right) from the centre of respective bread samples: a) air-cooled control, b) air-cooled sourdough, c) vacuum-cooled control, d) vacuum-cooled sourdough

partially baked bread, baking is short and the starch granule swelling is partial. On the other hand, vacuum cooling is achieved by boiling part of the bread moisture under reduced pressure. The process is said to allow starch gelatinization to complete, due to partial microcrystallization of the starch fraction (42). The presence of leached amylose from starch granule may act as a cement that prevents straining caused by the contraction of gluten network during post-baking cooling. Hence, vacuum cooling results in improved loaf expansion (21). The risk of contraction and structure collapse is additionally lessened due to the homogeneous internal temperature distribution in vacuum cooling (19). Our finding is that vacuum cooling noticeably improves crumb porosity of partially baked composite bread only when the formulation contains sourdough. We assume that the sourdough addition enhanced the formation of foam structure in the dough, while vacuum cooling helped in stabilization of a porous structure in baked crumb. Barley sourdough application in wheat bread has several beneficial effects including dough development (14). EPS produced by L. reuteri improve dough stability and gas retention through a structure build-up and interactions with the gluten network.

Furthermore, the interaction of sourdough addition and vacuum cooling somewhat influenced crust lightness $L^{*}(\mathrm{p}=0.001)$. This combination led to the lightest crust colour, $3 \%$ lighter than of the air-cooled sourbread. 
Sourdough addition changes dough $\mathrm{pH}$, and amounts of reducing sugars and free amino acids (11) that contribute to crust colouration. Shorter baking time after vacuum cooling nullified the browning effect of sourdough addition. Nowadays, baking to lighter colour has been advised for minimizing the formation of potentially carcinogenic compounds by heat (44). Our results show that the combination of the addition of barley sourdough fermented by L. reuteri and vacuum cooling can benefit crust colour, but also crumb cell structure and bread shape.

\section{MAP composition and microbial spoilage of partially baked bread}

The general recommendation for MAP of bakery products is a mixture of $60 \% \mathrm{CO}_{2} / 40 \% \mathrm{~N}_{2}$ (45). The level of $\mathrm{CO}_{2}$ in the packaging of our bread samples at the beginning of storage was $(61.5 \pm 1.5) \%$ and did not significantly differ between samples ( $p>0.05$ ). Some oxygen (on average $2.8 \%$ ) remained trapped in the spongy structure of our bread samples. Such level of residual oxygen is typical for bread in MAP, since the use of vacuum is limited due to its crushing effect on the bread (45).

Total aerobic bacterial count as well as spores of mesophilic bacteria were below 3.0 log CFU/g in all bread samples during entire storage period. Nonetheless, control samples, air or vacuum cooled, had visible moulds on the 30th day of storage, which was confirmed by mould count test $(2.0 \log \mathrm{CFU} / \mathrm{g})$. In agreement with our results, Khoshakhlagh et al. (17) demonstrated an ambient shelf life of partially baked sangak bread of about 21 days by using MAP under high $\mathrm{CO}_{2}$ volume fraction (75 \%). Vlášek et al. (46) reported that the $\mathrm{CO}_{2}$ atmosphere is able to suppress the development of mould for more than 15 days on gluten and gluten-free bread. Apart from the MAP effect, the extended shelf life of our products can be due to the use of ethanol as an active component to lower or control the growth of mycological entities. Using a spray technique, a rapid vaporisation of ethanol occurred within the headspace immediately after sealing the package. Such an environment can delay mould growth and ensure extended shelf life of the product. Hempel et al. (47) concluded that the use of ethanol surface sprays ( $3 \mathrm{~mL}$ by direct spraying), but particularly ethanol emitters $(3 \mathrm{~mL}$ of ethanol gel in LDPE-based sachets), reduces mycological counts in the bread stored in MAP $\left(10 \% \mathrm{CO}_{2} / 90 \% \mathrm{~N}_{2}\right)$. Furthermore, the use of ethanol in packs produces no negative sensory effect of packaged bread (32). Vacuum cooling is considered more hygienic since air only goes into the vacuum chamber at the end of the process when the vacuum chamber is opened to release the vacuum (19). The absence of such protection in our case could be due to a fact that both vacuum and MAP chamber were not directly connected to the baking oven and bread had to be transferred manually. Although protective handling was ensured during this manipulation as much as possible, samples could be contaminated.

Sourdough samples remained mould-free during 30 days of storage. After similar time, 27 days in MAP at $20^{\circ} \mathrm{C}$, mould, Gram-positive cocci, Coccobacillus or Bacillus growth on wholewheat bread with sourdough was reported by Fik et al. (48). Among others, the prolonged protective microbial effect derives from sourdough LAB producing organic acids and other antifungal and antibacterial substances. It was demonstrated in vitro and in situ that $L$. reuteri can delay fungal growth in bakery products $(7,10)$. Moreover, L. reuteri can inhibit the growth of Gram-positive and -negative bacteria by producing and excreting the antimicrobial compound reuterin $(11)$ as well as various fatty acids (7).

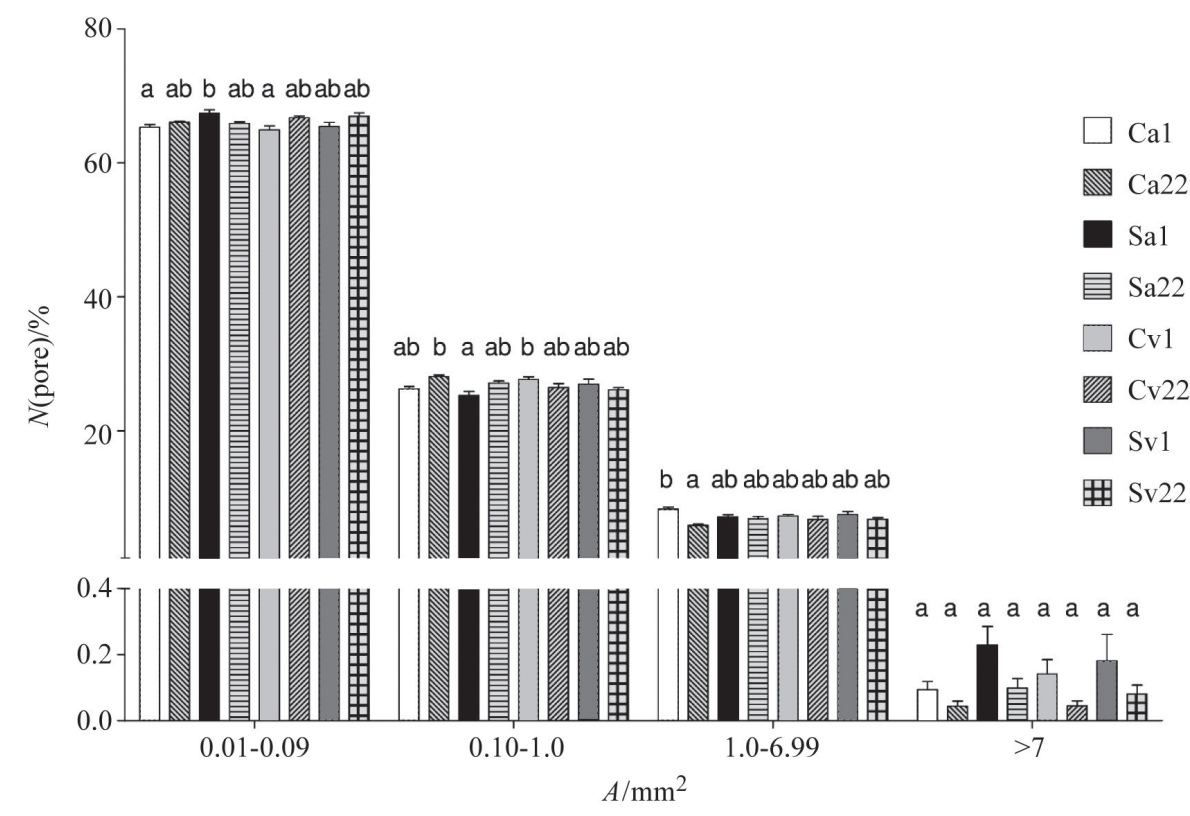

Fig. 3. Number of pores as a percentage of the total pore number for the selected classes. C=control formulation, $\mathrm{S}=$ formulation with sourdough, a=air cooling, v=vacuum cooling; 1 and $22=$ days of storage. Vertical bars represent standard deviation $(N=8)$. Different letters indicate significant difference between mean values within the same class $(p<0.05)$ 
Our results also show that the sourdough addition was more effective than the vacuum cooling in prolonging microbial shelf life of partially baked bread stored at ambient temperature in MAP. These findings are supported by previous conclusion of Karaoğlu et al. (49) that unless partially baked bread is stored at refrigerator temperature, the use of a $\mathrm{pH}$-reducing antimicrobial agent is crucial in bread preservation.

\section{Bread quality during storage}

Generally, moisture and texture are the most sensitive quality attributes of partially baked bread, which deteriorate in dependence of formulation and storage conditions. To investigate quality changes during MAP storage of partially baked bread with native and fermented barley flour depending on cooling technique, moisture content, shape, crumb structure and firmness were monitored, as well as sensory profile of sourbread for 30 days and control bread for 22 days (as moulds were present on the 30th day). Bread moisture content was not affected by sourdough addition $\mathrm{r}$ the cooling process ( $\mathrm{p}>0.05)$. Primo-Martín et al. (20) observed that vacuum cooling resulted in bread with lower moisture content in the crust than the air-cooled bread. However, we applied shorter rebaking of vacuum-cooled bread samples so their overall moisture content did not differ from air-cooled samples. Nonetheless, moisture content decreased with storage time $(\mathrm{p}<0.05)$ in all our samples. Moisture content of fresh bread was $(35.6 \pm 0.4) \%$. Statistically significant decrease in average moisture content to $(33.9 \pm 0.4) \%$ was determined on the 15th day of storage, and remained about the same, $(33.9 \pm 0.1) \%$ until the 30th day, probably due to low water vapour permeability of the PA/PE film (22). Such moisture loss of about $5 \%$ should be acceptable for both consumers and producers. Similarly, Fik et al. (48) found $6.6 \%$ moisture decrease of wholemeal bread in MAP after 14 days at $20^{\circ} \mathrm{C}$. Somewhat higher moisture loss within only 6 days in partially baked sangak bread was reported by Khoshakhlagh et al. (17) but this could be due to much higher initial bread moisture content. Moreover, our bread samples contained barley flour $\beta$-glucans, which have high water retention capacity (50). Different from our results, Le-Bail et al. (21) showed that vacuum-cooled bread exhibited higher moisture loss than conventionally cooled bread during 21 days of storage, but their bread samples were wrapped in ordinary plastic pouches and stored at $4{ }^{\circ} \mathrm{C}$.

Changes in crumb structure during storage were characterised by the shrinkage of the big pores (Fig. 3). Consequently, the mean pore area decreased on average from 0.29 to $0.25 \mathrm{~mm}^{2}$ ( $\left.\mathrm{p}<0.001\right)$ during 22 days of storage, and the pore density in the selected field of view increased from 91.2 to 105.2 per $\mathrm{cm}^{2}$. In the same period, a decrease of average bread shape from 0.58 to $0.56(\mathrm{p}=0.048)$ was detected. Nevertheless, total pore area fraction did not change significantly. In agreement with our results, Crowley et al. (35) found a significant increase in the number of cells per $\mathrm{cm}^{2}$ and significant decrease in the mean cell area of sourdough bread during 74-hour room storage. They attributed these changes to crumb grain shrinkage. The dehydration induces shrinking and then global contraction of the crumb matrix (40). We assume that MAP prolonged
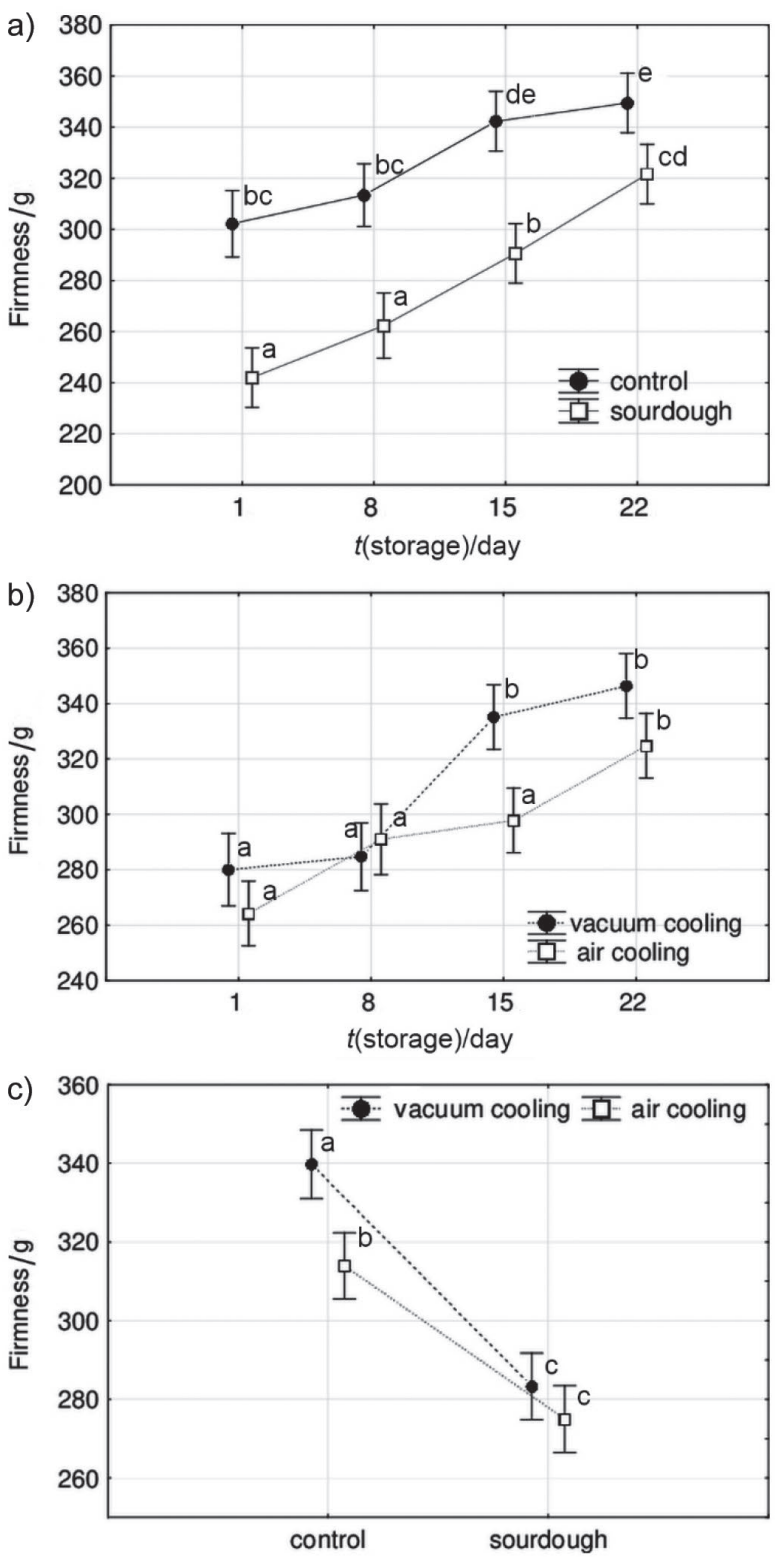

Fig. 4. Crumb firmness influenced by: a) sourdough addition and storage time, b) cooling method and storage time, and c) interaction of sourdough addition and cooling method. Vertical bars represent $0.95 \%$ confidence interval. Different letters indicate significant differences between mean values $(\mathrm{p}<0.05)$

intactness of crumb structure of partially baked bread due to low moisture loss.

Crumb firmness was influenced by many interactions: sourdough addition and storage time $(\mathrm{p}=0.05)$ (Fig. 4a), the cooling method and storage time $(\mathrm{p}=0.007)$ (Fig. 4b), as well as sourdough addition and the cooling method $(\mathrm{p}=0.04)$ (Fig. 4c). Compared to control bread, crumb of the sourbread samples was substantially softer, but this difference decreased with storage (Fig. 4a). Crumb of fresh sourbread samples was on average $20 \%$ softer than of the fresh control samples, while after 22 days of storage this difference was only $8 \%$. The crumb firmness of our fresh bread samples was somewhat higher than previously reported of wheat bread with sourdough fermented 
by $L$. reuteri (7), since here the crumb of partially baked was firmer than of directly baked bread (46). The observed crumb softening after the addition of sourdough could be attributed to a partial gluten proteolysis and formation of EPS in barley sourdough fermented by L. reuteri. EPS can improve the viscoelastic properties of dough, increase loaf volume, reduce crumb hardness, and prolong shelf life of bread $(12,13)$. Previously, Zhao et al. (41) demonstrated that the inclusion of a small amount $(6 \%)$ of sourdough fermented by $L$. reuteri in the bread formulation is not sufficient to affect hardness of wholemeal wheat bread. Nevertheless, we used sourdough in higher amounts as well as barley flour as a substrate. Novotni et al. (51) demonstrated that the improvement of crumb texture of frozen partially baked bread depends on sourdough starter and its amount.

Overall, the cooling technique did not significantly affect crumb firmness of fresh samples, or the extent of total firming. Still, application of vacuum cooling of control bread resulted in firmer crumb (Fig. 4b) than by air cooling, but not in sourbread. Previously, Le-Bail et al. (21) reported that vacuum cooling increased crumb hardness of wholewheat sourbread and they attributed it to higher moisture loss. As moisture content among our fresh bread samples did not differ, crumb firmness of fresh samples did not depend on cooling technique either. Also, Primo-Martín et al. (20) described vacuum-cooled bread (crumb with crust) as harder than the air-cooled bread on the basis of instrumental measurements but not in sensory evaluation.

Although no significant effect of cooling technique on total firming was observed, the firming dynamics somewhat differed (Fig. 4b). Firmness of vacuum-cooled bread samples stayed almost unchanged for 8 days of storage, while after 15 and 22 days, they were significantly firmer (12 and $6 \%$ respectively) than air-cooled samples. This could be related to moisture change on the 15 th day, which was somewhat higher in the vacuum-cooled than in the air-cooled samples $(\mathrm{p}=0.07)$. Previously, Le-Bail et al. (21) demonstrated $10 \%$ faster staling kinetics of vacuum-cooled than conventionally cooled bread, but similar melting enthalpy value among bread samples after 12 days of storage at $4{ }^{\circ} \mathrm{C}$. They ascribed this phenomenon to the quickness of vacuum cooling, which may in turn favour the formation of numerous nuclei of amylopectin crystallites, resulting in a larger amount of recrystallized amylopectin.

On the 15th day of storage, besides moisture loss, crumb firming (15-22\%) was significant in all samples except air-cooled control ( $9 \%$, data not shown). Firming of bread in MAP has been shown previously, but its extent varies depending on bread formulation. Khoshakhlagh et al. (17) reported significant crumb hardening of sangak bread during 21 days of ambient storage in MAP. Fik et al. (48) showed significant increase in crumb hardness of wholemeal wheat bread after 8 days of storage in MAP, developing further steadily, and after 32 days of storage, it increased up to $126 \%$ compared to fresh bread.

In spite of our expectations, sourdough addition did not postpone crumb firming. The extent of crumb firming in 30 days of storage of both vacuum- and air-cooled sourbread samples was $42-47 \%$, respectively (data not shown). Among all samples, air-cooled control bread showed the smallest extent of total firming ( $11 \%$ in 22 days of storage). Torrieri et al. (13) demonstrated that higher amount of sourdough (30 \%) obtained with selected EPS-producing LAB strains had a protective effect on bread staling, whereas lower sourdough amount (20\%), which we added, was insufficient for protecting the mechanical properties of bread during storage. Moreover, the use of fermented barley flour over native barley flour might have some disadvantages. It was shown that native barley flour high in $\beta$-glucans is helpful in delaying the staling rate of bread when used at the $20 \%$ level, even if it increased the firmness of fresh product (1). This outcome has been ascribed to the presence of $\beta$-glucans, which might diminish starch crystallisation due to their high hydrophilicity. However, molecular mass of the present $\beta$-glucans influences their ability to retard staling, i.e. the higher the molecular mass of $\beta$-glucans the better the improvement of crumb softness during storage (47). Generally, the use of sourdough decreases the average molecular mass of $\beta$-glucans in the bread compared to the respective bread samples without sourdough (9). Still, crumb of our sourbread was softer (on average by $12 \%$ ) than of control samples during the entire mould-free storage period.

The perceived freshness of bread is one of the key determinants of consumer product acceptability and preference (52). ANOVA did not demonstrate the significant difference among panellists' responses $(\mathrm{p}>0.05)$, while it designated some differences between the sensory attributes of bread samples depending on the formulation and cooling process (Table 2). Sourdough addition resulted in significant differences in yeast odour, yeast taste, sour taste, and aftertaste $(\mathrm{p}<0.05)$. Control samples had pronounced yeasty taste and odour, whereas sourbread samples had sour taste and aftertaste. The use of sourdough is reported to improve bread aroma, but high acidity might negatively affect consumer preference (52). Despite that, the average score shows that the sourness intensity was very low (Table 2 ). Higher acidity can mask the intense flavour and taste of barley (4), and reduce mould and Bacillus development (12). Moreover, the interaction of sourdough addition and vacuum cooling was proven significant for crumbliness $(\mathrm{p}=0.02)$. Vacuum cooling prevented crumbliness of sourbread, but it did not affect crumbliness of control bread. This finding is very important because crumbliness is not a desirable attribute as it indicates bread staling and reduced eating quality. The difference in odour depending on cooling technique was observed in sourbread but not in control samples. Vacuum-cooled sourbread had less pronounced acid odour $(p=0.006)$ than the air-cooled sourbread. Loss of product aroma due to vacuum cooling was claimed by Sun and Zheng (19). However, this might be helpful for sourbread as excessive acid odour is not desirable. Although vacuum cooling affects bread aroma, here it did not significantly affect the taste attributes ( $p>0.05)$. Kratochvil and Holas (53) found no significant differences between the taste of vacuum- and conventionally cooled wheat bread samples, which is in agreement with our findings. Considering ANOVA results, there were no significant changes in bread flavour or crumbliness during storage ( $p>0.05$ ). High intensity of mouldy or dusty odour was not reported for any sample. Fik et al. (48) also reported acceptable sensory quality of wholemeal bread in MAP for 
Table 2. Mean values of bread sensory attributes

\begin{tabular}{|c|c|c|c|c|c|c|c|}
\hline \multirow{2}{*}{ Attribute } & \multirow{2}{*}{ Description } & \multicolumn{4}{|c|}{ Sample } & \multicolumn{2}{|c|}{$\mathrm{p}$-value } \\
\hline & & $\mathrm{Ca}$ & $\mathrm{Cv}$ & $\mathrm{Sa}$ & $\mathrm{Sv}$ & Sourdough & Cooling \\
\hline \multicolumn{8}{|l|}{ Odour } \\
\hline Dusty & Aromatics associated with dry and musty closed spaces & 0.70 & 0.71 & 0.99 & 0.95 & & \\
\hline Mouldy & Aromatics associated with damp and stale air & 0.11 & 0.21 & 0.40 & 0.13 & & \\
\hline Yeasty & Aromatics associated with yeast-fermented dough & 1.48 & 1.39 & 1.00 & 0.95 & 0.025 & \\
\hline Vinegar & Sour aromatics associated with vinegar & 0.32 & 0.30 & 0.52 & 0.20 & & \\
\hline Dairy & Aromatics associated with products of cow's milk & 0.24 & 0.18 & 0.30 & 0.23 & & \\
\hline Overall & Overall odour intensity & 3.89 & 3.91 & 3.82 & 3.71 & & \\
\hline \multicolumn{8}{|l|}{ Taste } \\
\hline Sour & Basic taste & 0.38 & 0.45 & 1.06 & 0.92 & 0.003 & \\
\hline Bitter & Basic taste & 0.61 & 0.70 & 0.64 & 0.48 & & \\
\hline Yeasty & Taste associated with yeast-fermented dough & 0.82 & 0.77 & 0.47 & 0.51 & 0.039 & \\
\hline Aftertaste & Intensity of unpleasant aftertaste, after chewing the sample & 0.27 & 0.29 & 0.63 & 0.50 & 0.005 & \\
\hline \multicolumn{8}{|l|}{ Texture } \\
\hline Crumbliness & $\begin{array}{l}\text { The amount of crumbles produced after rubbing half a } \\
\text { slice three times in a downward direction with index } \\
\text { finger }\end{array}$ & 1.30 & 1.29 & 1.83 & 1.13 & & 0.002 \\
\hline
\end{tabular}

$\mathrm{C}=$ control, $\mathrm{S}=$ sourdough formulation, $\mathrm{a}=$ air cooling, $\mathrm{v}=$ =vacuum cooling. ANOVA was significant $\mathrm{at} \mathrm{p}<0.05$

almost four weeks. A modified atmosphere has a beneficial effect on the stability of the stored bakery products $(21,45)$. Otherwise, the storage of sourdough bread without MAP at $4{ }^{\circ} \mathrm{C}$ for 21 days significantly affects the sourness, fresh bread flavour, and stale bread flavour and texture attributes (12).

In order to compare bread quality at different storage times, principal component analysis was performed on the results of descriptive sensory analysis, bread moisture content and instrumentally determined firmness and shape. Fig. 5 shows the results obtained for the first two principal components (PC1 and PC2), with eigenvalues of 5.10 and 3.03 , respectively, which explained $58.1 \%$ of total variability. The PC1, explaining about $36 \%$ of variance, was positively correlated with the aftertaste, sour taste, dusty odour, and mouldy odour, while it was negatively correlated with yeasty taste, yeasty and overall odour (Fig. 5b). Control and fresh sourbread samples were separated from the stored sourbread samples along PC1 (left and right side, respectively) (Fig. 5a). As expected, fresh bread samples were not related to indicators of stale bread (firmness, crumbliness, dusty or mouldy odour). Fresh sourbread samples were characterised by dairy odour and overall odour intensity, as well as high moisture content and shape.

The PC2, explaining about $22 \%$ of variance, was positively correlated with firmness and bitter taste, and negatively with dusty odour. It is important to notice that fresh sourbread samples were characterised as softest, regardless of the cooling technique. The PC3 (not shown), with eigenvalue of 2.32 and explaining about $17 \%$ of variance, was negatively correlated with bread crumbliness. Stored vacuum-cooled sourbread samples were the most related to PC3, being the least crumbly. During storage, there was a trend of decreasing the intensity of bread overall odour, dairy odour, shape and moisture, which characterise fresh
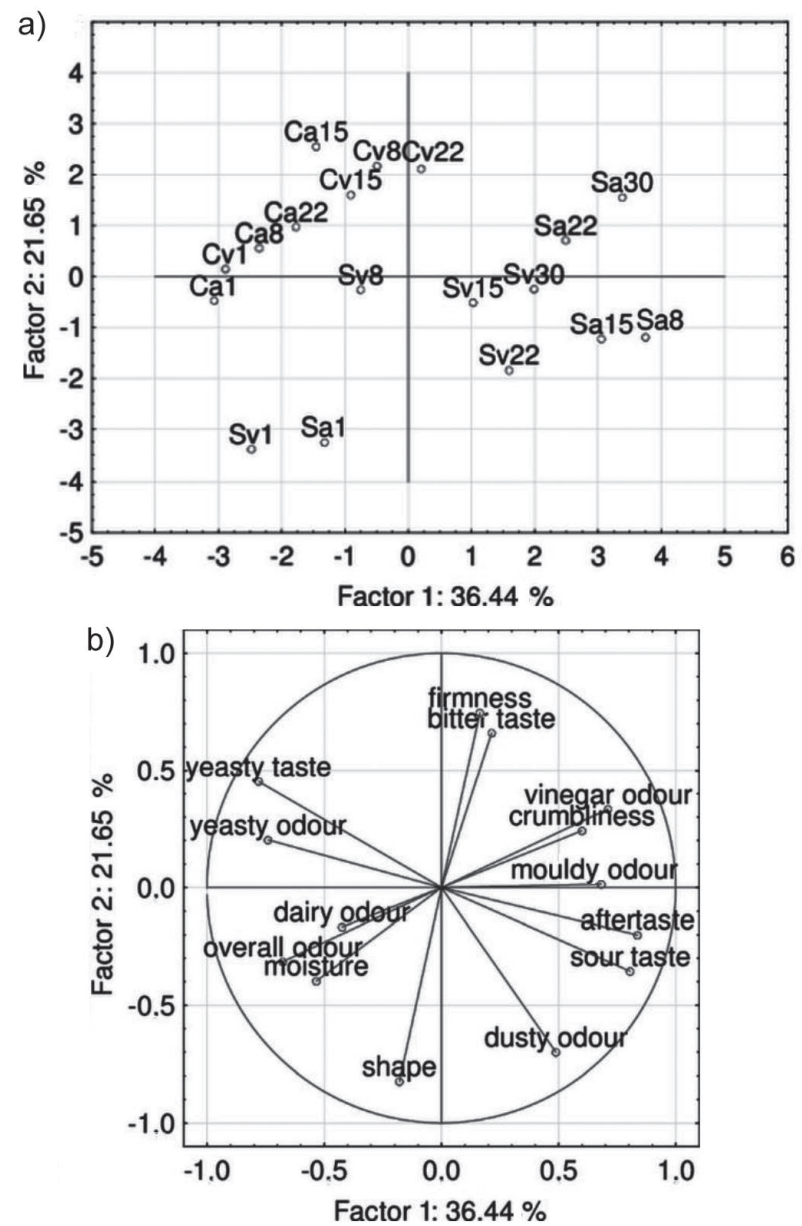

Fig. 5. Loadings (a) and score plot (b) of the first two principal components calculated by principal component analysis of bread characteristics during storage. Loadings: $\mathrm{C}=$ control formulation, $\mathrm{S}=$ formulation with sourdough, $\mathrm{a}=$ air cooling, $\mathrm{v}=$ vacuum cooling, $1-30=$ days of storage 
bread, and increasing bread firmness, crumbliness, bitter and sour taste. However, the changes in sensory attributes were small and acceptable.

\section{Conclusions}

In this study the impact of barley sourdough fermentation and vacuum cooling on the shelf life quality of composite partially baked bread during 30 days of ambient storage in modified atmosphere was investigated. During storage, bread flavour did not change significantly; however, continuous crumb firming limited bread shelf life the most. The addition of barley sourdough fermented by Lactobacillus reuteri improved initial crumb softness and extended microbial safety of composite bread during ambient storage, as proven by both instrumental and microbiological tests. Crumb softness was ensured for at least 15 days, and mould- and bacteria- free storage of partially baked bread for 30 days. For these reasons, the addition of barley sourdough fermented by Lactobacillus reuteri is preferable over vacuum cooling for extension of partially baked bread shelf life during ambient storage in MAP. Nonetheless, vacuum cooling combined with barley sourdough addition controled crust browning, prevented crumbliness, improved bread shape and crumb structure, and reduced sour taste. Thus, this combination can be successfully applied in a production of partially baked bread. Future studies should address optimal barley sourdough amount and starter to minimize bread firming during storage. Barley flour is underutilized flour with numerous health benefits and should be further exploited for potential use in production of bread with extended shelf life.

\section{Acknowledgement}

This research was financially supported by the Croatian Science Foundation, project VH/VT 09/01/279. The authors wish to thank Lidija Drobac and staff of Laboratory for Unit Operations, Faculty of Food Technology and Biotechnology, University of Zagreb, for their precious technical support, and members of sensory panel for their contribution.

\section{References}

1. Smith JP, Phillips D, El-Khoury W, Koukoutsis J, El-Khoury A. Shelf life and safety concerns of bakery products - A review. Crit Rev Food Sci Nutr. 2004;44:19-55. https://doi.org/10.1080/10408690490263774

2. Gujral HS, Gaur S, Rosell CM. Note: Effect of barley flour, wet gluten and ascorbic acid on bread crumb texture. Food Sci Technol Int. 2003;9:17-21.

https://doi.org/10.1177/1082013203009009001003

3. Kurek MA, Wyrwisz J, Wierzbicka A. Optimization of beta-glucan and water content in fortified wheat bread using response surface methodology according to staling kinetics. LWT - Food Sci Technol. 2017;75:352-7.

https://doi.org/10.1016/j.lwt.2016.09.008

4. Marklinder I, Haglund $\AA$, Johansson L. Influences of lactic acid bacteria on technological, nutritional, and sensory properties of barley sour dough bread. Food Qual Prefer. 1996;7:285-92. https://doi.org/10.1016/S0950-3293(96)00027-4

5. Škribić B, Milovac S, Dodig D, Filipčev B. Effects of hull-less barley flour and flakes on bread nutritional composition and senso- ry properties. Food Chem. 2009;115:982-8. https://doi.org/10.1016/j.foodchem.2009.01.028

6. Mariotti M, Garofalo C, Aquilanti L, Osimani A, Fongaro L, Tavoletti S, et. al. Barley flour exploitation in sourdough bread-making: A technological, nutritional and sensory evaluation. LWT - Food Sci Technol. 2014;59:973-80. https://doi.org/10.1016/j.lwt.2014.06.052

7. Jonkuvienė D, Vaičiulytė-Funk L, Šalomskienė J, Alenčikienė G, Mieželienè A. Potential of Lactobacillus reuteri from spontaneous sourdough as a starter additive for improving quality parameters of bread. Food Technol Biotechnol. 2016;54:342-50. https://doi.org/10.17113/ftb.54.03.16.4143

8. Katina K, Salmenkallio-Marttila M, Partanen R, Forssell P, Autio K. Effects of sourdough and enzymes on staling of high-fibre wheat bread. LWT - Food Sci Technol. 2006;39:479-91. https://doi.org/10.1016/j.lwt.2005.03.013

9. Rieder A, Holtekjølen AK, Sahlstrøm S, Moldestad A. Effect of barley and oat flour types and sourdoughs on dough rheology and bread quality of composite wheat bread. J Cereal Sci. 2012;55:44-52. https://doi.org/10.1016/j.jcs.2011.10.003

10. Le Lay C, Mounier J, Vasseur V, Weill A, Le Blay G, Barbier G, Coton E. In vitro and in situ screening of lactic acid bacteria and propionibacteria antifungal activities against bakery product spoilage molds. Food Control. 2016;60:247-55. https://doi.org/10.1016/j.foodcont.2015.07.034

11. Talarico TL, Axelsson Novotny J, Fiuzat M, Dobrogosz WJ. Utilization of glycerol as a hydrogen acceptor by Lactobacillus reuteri: Purification of 1-,3-propanediol:NAD ${ }^{+}$oxidoreductase. Appl Environ Microbiol. 1990;56:943-8.

12. Di Monaco R, Torrieri E, Pepe O, Masi P, Cavella S. Effect of sourdough with exopolysaccharide (EPS)-producing lactic acid bacteria (LAB) on sensory quality of bread during shelf life. Food Bioproc Tech. 2015;8:691-701.

https://doi.org/10.1007/s11947-014-1434-3

13. Torrieri E, Pepe O, Ventorino V, Masi P, Cavella S. Effect of sourdough at different concentrations on quality and shelf life of bread. LWT - Food Sci Technol. 2014;56:508-16. https://doi.org/10.1016/j.lwt.2013.12.005

14. Vrana Špoljarić I, Maričić N, Novotni D, Ajredini S, Voučko B, Ćurić D. Characteristics of barley sourdough during frozen storage. Proceedings of the 8th International Congress Flour-Bread 15 and 10th Croatian Congress of Cereal Technologists; 2015 October 29-30; Opatija, Croatia. Osijek, Croatia: University of Osijek; 2016. pp. 21-32.

15. Gray JA, Bemiller JN. Bread staling: Molecular basis and control. Compr Rev Food Sci Food Saf. 2003;2:1-21. https://doi.org/10.1111/j.1541-4337.2003.tb00011.x

16. Bosmans GM, Lagrain B, Ooms N, Fierens E, Delcour JA. Storage of parbaked bread affects shelf life of fully baked end product: ${ }^{1}{ }^{1}$ H NMR study. Food Chem. 2014;165:149-56. https://doi.org/10.1016/j.foodchem.2014.05.056

17. Khoshakhlagh K, Hamdami N, Shahedi M, Le-Bail A. Quality and microbial characteristics of part-baked sangak bread packaged in modified atmosphere during storage. J Cereal Sci. 2014;60:42-7. https://doi.org/10.1016/j.jcs.2014.01.014

18. Wang L, Sun DW. Rapid cooling of porous and moisture foods by using vacuum cooling technology. Trends Food Sci Technol. 2001;12:174-84. https://doi.org/10.1016/S0924-2244(01)00077-2

19. Sun DW, Zheng L. Vacuum cooling technology for the agri-food industry: Past, present and future. J Food Eng. 2006;77:203-14. https://doi.org/10.1016/j.jfoodeng.2005.06.023

20. Primo-Martín C, de Beukelaer H, Hamer RJ, van Vliet T. Fracture behaviour of bread crust: Effect of bread cooling conditions. 
J Food Eng. 2008;8:285-90.

https://doi.org/10.1016/j.jfoodeng.2008.05.005

21. Le-Bail A, Leray G, Perronnet A, Roelens G. Impact of the chilling conditions on the kinetics of staling of bread. J Cereal Sci. 2011;54:13-9.

https://doi.org/10.1016/j.jcs.2010.10.007

22. ICC Method 126/1. Method for using the Brabender amylograph. Vienna, Austria: International Association for Cereal Chemistry (ICC); 2009.

23. ICC Method 115/1. Method for using the Brabender farinograph. Vienna, Austria: International Association for Cereal Chemistry (ICC); 2009.

24. ICC Method 114/1. Method for using the Brabender extensograph. Vienna, Austria: International Association for Cereal Chemistry (ICC); 2009.

25. ISO 15214:1998. Microbiology of food and animal feeding stuffs - Horizontal method for the numeration of mesophilic lactic acid bacteria - Colony-count technique at 30 degrees C. Geneva, Switzerland: International Organization for Standardization (ISO); 1998

26. ISO 15105-1:2007. Plastics - Film and sheeting - Determination of gas-transmission rate - Part 1: Differential-pressure methods. Geneva, Switzerland: International Organization for Standardization (ISO); 2007.

27. ICC Method 125. Method of determining the count of aerobic mesophilic bacteria (plate count method). Vienna, Austria: International Association for Cereal Chemistry (ICC); 2009.

28. ICC Method 144. Enumeration of spores of mesophilic bacteria. Vienna, Austria: International Association for Cereal Chemistry (ICC); 2009.

29. ICC Method 139. Determination of fungus germ count (plate count method). Vienna, Austria: International Association for Cereal Chemistry (ICC); 2009.

30. AACC Method 44-15.02. Moisture - Air-oven methods. St. Paul, MN, USA: American Association of Cereal Chemists (AACC) International; 2010.

31. AACC Method 10-05.01. Guidelines for measurement of volume by rapeseed displacement. St. Paul, MN, USA: American Association of Cereal Chemists (AACC) International; 2001.

32. ImageJ, v. 1.51j8, National Institute of Health, Bethesda, MD, USA; 2017. Available from http://rsb.info.nih.gov/ij/.

33. SilkyPix Developer Studio Pro8, v. 8.0.6.0. Tegelen, The Netherlands: Globell B.V.; 2017. Available from: http://www.silkypix.eu.

34. Otsu N. A threshold selection method from gray-level histograms. IEEE Trans Syst Man Cybern. 1979; SMC-9:62-6.

35. Crowley P, Schober TJ, Clarke CI, Arendt EK. The effect of storage time on textural and crumb grain characteristics of sourdough wheat bread. Eur Food Res Technol. 2002;214:489-96. https://doi.org/10.1007/s00217-002-0500-7

36. AACC Method 74-09.01. Measurement of bread firmness by universal testing machine. St. Paul, MN, USA: American Association of Cereal Chemists (AACC) International; 1999.

37. CIE 15: Technical Report: Colorimetry. Vienna, Austria: International Commission on Illumination; 2004.

38. ISO 8589:2007. Sensory analysis - General guidance for the design of test rooms. Geneva, Switzerland: International Organization for Standardization (ISO); 2007.

39. STATISTICA, v. 12, StatSoft, Inc, Tulsa, OK, USA; 2012. Available from: http://www.statsoft.com.
40. Zannini E, Garofalo C, Aquilanti L, Santarelli S, Silvestri G, Clementi F. Microbiological and technological characterization of sourdoughs destined for bread-making with barley flour. Food Microbiol. 2009;26:744-53. https://doi.org/10.1016/j.fm.2009.07.014

41. Zhao CJ, Kinner M, Wismer W, Gänzle MG. Effect of glutamate accumulation during sourdough fermentation with Lactobacillus reuteri on the taste of bread and sodium-reduced bread. Cereal Chem. 2015;92:224-30. https://doi.org/10.1094/CCHEM-07-14-0149-R

42. Bradshaw W. Modulated vacuum cooling for bakery products. Bakers Dig. 1976;50:26-31.

43. Ben Aissa MF, Monteau JY, Perronnet A, Roelens G, Le Bail A. Volume change of bread and bread crumb during cooling, chilling and freezing, and the impact of baking. J Cereal Sci. 2010;51:115-9. https://doi.org/10.1016/j.jcs.2009.10.006

44. Keramat J, LeBail A, Prost C, Jafari M. Acrylamide in baking products: A review article. Food Bioproc Tech. 2011;4:530-43. https://doi.org/10.1007/s11947-010-0495-1

45. Galić K, Ćurić D, Gabrić D. Shelf life of packaged bakery goods A review. Crit Rev Food Sci Nutr. 2009;49:405-26. https://doi.org/10.1080/10408390802067878

46. Vlášek V, Langová J, Štencl J. Effect of modified atmosphere packaging on stability of three kinds of bread. Acta Univ Agric Silvic Mendelianae Brun. 2013;61:1881-7. https://doi.org/10.11118/actaun201361061881

47. Hempel AW, O'Sullivan MG, Papkovsky DB, Kerry JP. Use of smart packaging technologies for monitoring and extending the shelf-life quality of modified atmosphere packaged (MAP) bread: Application of intelligent oxygen sensors and active ethanol emitters. Eur Food Res Technol. 2013;237:117-24. https://doi.org/10.1007/s00217-013-1968-z

48. Fik M, Surówka K, Maciejaszek I, Macura M, Michalczyk M. Quality and shelf life of calcium-enriched wholemeal bread stored in a modified atmosphere. J Cereal Sci. 2012;56:418-24. https://doi.org/10.1016/j.jcs.2012.06.006

49. Karaoğlu MM, Gürbuz Kotancilar H, Gurses M. Microbiological characteristics of part-baked white pan bread during storage. Int J Food Prop. 2005;8:355-65. https://doi.org/10.1081/JFP-200060239

50. Skendi A, Biliaderis CG, Papageorgiou M, Izydorczyk MS. Effects of two barley $\beta$-glucan isolates on wheat flour dough and bread properties. Food Chem. 2010;119:1159-67. https://doi.org/10.1016/j.foodchem.2009.08.030

51. Novotni D, Čukelj N, Smerdel B, Ćurić D. Quality attributes and firming kinetics of partially baked frozen wholewheat bread with sourdough. Int J Food Sci Technol. 2013;48:2133-42. https://doi.org/10.1111/ijfs.12197

52. Heenan SP, Dufour JP, Hamid N, Harvey W, Delahunty CM. The sensory quality of fresh bread: Descriptive attributes and consumer perceptions. Food Res Int. 2008;41:989-97. https://doi.org/10.1016/j.foodres.2008.08.002

53. Kratochvil J, Holas J. Effect of vacuum cooling on the content of aroma substances and sensory properties of bread. Sb UVTIZ Potravin Vedy. 1984;2:241-51. 